\title{
Mycoplasma genitalium Infection Prevalence in Patients with Human Immunodeficiency Virus
}

\author{
Rini Rasianti, ${ }^{1}$ Hartati Dharmadji, ${ }^{2}$ Risa Miliawati, ${ }^{2}$ Diah Puspitosari, ${ }^{1}$ Feilicia Henrica Teja, ${ }^{1}$ \\ Rasmia Rowawi, ${ }^{2}$ Rahmatdinata, ${ }^{2}$ Tony Djajakusumah ${ }^{2}$ \\ ${ }^{1}$ Faculty of Medicine, Universitas Padjdajaran-Dr. Hasan Sadikin General Hospital \\ ${ }^{2}$ Department of Dermatology and Venereology, Faculty of Medicine, Universitas Padjajaran-Dr. Hasan Sadikin General \\ Hospital
}

$\begin{array}{ll}\text { Abstract } & \text { Objective: To determine the prevalence of Mycoplasma genitalium (M. } \\ \text { genitalium) infection in HIV positive patients by PCR examination in Teratai } \\ \text { Clinic of Dr. Hasan Sadikin General Hospital, Bandung in order to reduce sexually } \\ \text { transmitted diseases, especially M. genitalium infection in HIV positive patients. } \\ \text { Methods: This study was a cross-sectional study with consecutive sampling } \\ \text { methods. Eighty one HIV positive patients attending the Teratai Clinic of Dr. } \\ \text { Hasan Sadikin General Hospital, Bandung were recruited to be the subjects of } \\ \text { this study. All subjects underwent history taking, physical examination, and PCR } \\ \text { examination for M. genitalium. Specimens were taken from cervical smear in } \\ \text { females and first void urine in male. } \\ \text { Results: The prevalence of M. genitalium based on the PCR examination in HIV } \\ \text { positive patients attended to Teratai Clinic Dr. Hasan Sadikin General Hospital } \\ \text { Bandung was 9\%. } \\ \text { Conclusions: Mycoplasmal infection identification based on PCR examination } \\ \text { Received: } \\ \text { should be considered for routine screening test to reduce the incidence of } \\ \text { sexually transmitted diseases in HIV positive patients. } \\ \text { Revised: } \\ \text { April 1, 2013 }\end{array}$

\section{Introduction}

Mycoplama genitalium ( $M$. genitalium) is the smallest bacterium, with a genome size of 580 $\mathrm{kb}$, of the Mollicutes Class (Mollis:soft, Cutis:skin, in Latin) that is mainly found in human genital tract. ${ }^{1,2}$ Several studies have already shown that M. genitalium is a sexually transmitted organism that causes asymptomatic or non-gonococcal urethritis (NGU) in males as well as cervicitis, endometritis, pelvic inflammatory disease in females. ${ }^{3-7}$

Mycoplama genitalium infection can be detected through culture, serological, and polymerase chain reaction (PCR) examinations. The culture examination may take several weeks or even months to grow M. genitalium.

\section{Correspondence:}

Rini Rasianti, Faculty of Medicine, Universitas Padjadjaran-

Dr. Hasan Sadikin General Hospital

Jl. Pasteur No. 38, Bandung, Indonesia

e-mail: r_rasianti@yahoo.com
Hence, it cannot be used as a routine diagnostic tool in every day practice. In the serological examination, cross reactions may occur between $M$. genitalium and $M$. pneumoniae due to some similar structures, thereby decreasing the specificity of the test. The PCR examination can detect the microorganism in samples collected from the reproductive tracts in a highly sensitive, accurate, and specific manner. This leads to a situation where PCR is the only reliable diagnostic tool for $M$. genitalium infection. ${ }^{8}$ Currently, the PCR examination to detect $M$. genitalium is available for research only and not available comercially. ${ }^{9}$

Cross-sectional studies have shown a strong association between $M$. genitalium and HIV. ${ }^{10}$ $M$. genitalium may play an important role in the acquisition and transmission of HIV as also in other sexually transmitted diseases. Several in vitro studies have shown that the inflammatory response and mucosal disruption associated 
with $M$. genitalium infection will increase either the susceptibility or transmissibility, or both, to HIV infection. ${ }^{11}$

Research regarding the relationship between M. genitalium and HIV will provide knowledge on HIV cofactors that can be intervened. Studies among HIV positive patients in several clinics in Italy, Brazil, United States, and India have found that the prevalence rates of $M$. genitalium vary between $1 \%$ and $10 \%{ }^{10,12-15}$ There is no data on the prevalence $M$. genitalium in HIV positive patients in Indonesia, especially in West Java. The examination and treatment of M. genitalium infection in high-risk populations should be investigated as a potential strategy to prevent HIV. ${ }^{11}$ Therefore, a descriptive study was done to determine $M$. genitalium prevalence in HIV positive patients who visited Teratai Clinic of Dr. Hasan Sadikin General Hospital, Bandung through the use of PCR.

\section{Methods}

This study was an observational study with cross sectional design. The subjects were 81

Table 1 Distribution of All Participant Based on PCR Result

\begin{tabular}{lccc}
\hline \multirow{2}{*}{ Variable } & \multicolumn{2}{c}{ PCR M. genitalium } & Total \\
\cline { 2 - 3 } & Positive & Negative & $\mathbf{n}(\%)$ \\
\hline Sex & & & \\
Male & 4 & 44 & $48(59)$ \\
Female & 3 & 30 & $33(41)$ \\
$\quad$ Total (male+female) & 7 & 74 & $81(100)$ \\
Education & & & \\
No education & 0 & 0 & $0(0)$ \\
Elementary school & 0 & 4 & $4(5)$ \\
Junior high school & 1 & 3 & $4(5)$ \\
Senior high school & 3 & 38 & $41(51)$ \\
College/University & 3 & 29 & $32(39)$ \\
Occupation & & & \\
Entrepreneur & 3 & 32 & $35(43)$ \\
Employee & 0 & 21 & $21(26)$ \\
Commercial sex worker & 0 & 1 & $1(1)$ \\
Student & 1 & 0 & $1(1)$ \\
Not working & 3 & 20 & $23(29)$ \\
Marital status & & & \\
Single & 3 & 15 & $18(22)$ \\
Married & 3 & $45(56)$ \\
Widowers/widows & 1 & $18(22)$ \\
\hline
\end{tabular}

HIV positive patients who visited Teratai Clinic of Dr. Hasan Sadikin General Hospital Bandung who were taken in consecutive admission in July 2012. The HIV serostatus of the study population had already been determined and confirmed based on National HIV guideline in Teratai Clinic before this study. The inclusion criteria for this study were male and female HIV patients in
Teratai clinic who were sexually active. Female patients who were having her menstrual period were excluded from this study.

The study design was approved by the Research Ethics Committee of Health, Dr. Hasan Sadikin General Hospital, Bandung. The subjects were given a description on the research and if they were willing to participate in the study, they 
were asked to sign the informed consent. The subjects then underwent history taking, physical examination, and samples for PCR examination were collected from the first void urine in males and cervical swab in females.

The results were presented descriptively to determine the prevalence of $M$. genitalium based on PCR examination in HIV positive patients. The study was conducted at Teratai Clinic of Dr. Hasan Sadikin General Hospital, Bandung and the PCR examination for $M$. genitalium was performed at the Laboratory of Molecular Biology Department of Microbiology/Health Research Unit of the Faculty of Medicine, Universitas Padjadjaran, Bandung.

Thirty to fifty $m L$ first void urine samples were collected from male patients in sterile specimen collection manner after the patient had not urinated for 2 hours. The cervical swabs for female patients were collected using a specimen

Table 2 Sexual Behavior of Participants Based on PCR Result

\begin{tabular}{|c|c|c|c|}
\hline \multirow{2}{*}{ Variable } & \multicolumn{2}{|c|}{ PCR M. genitalium } & \multirow{2}{*}{$\begin{array}{l}\text { Total } \\
\text { n (\%) }\end{array}$} \\
\hline & Positive & Negative & \\
\hline \multicolumn{4}{|l|}{ Sexual orientation } \\
\hline Heterosexual & 6 & 66 & $72(89)$ \\
\hline Homosexual & 1 & 4 & $5(6)$ \\
\hline Bisexual & 0 & 4 & $4(5)$ \\
\hline \multicolumn{4}{|l|}{ Sexual practises } \\
\hline Genital-genital (GG) & 5 & 32 & $37(46)$ \\
\hline GG+Oral-genital (OG) & 1 & 31 & $32(39)$ \\
\hline OG+Anal-genital (AG) & 0 & 4 & $4(5)$ \\
\hline $\mathrm{GG}+\mathrm{OG}+\mathrm{AG}$ & 1 & 5 & $6(7)$ \\
\hline $\mathrm{GG}+\mathrm{OG}+\mathrm{AG}+$ Oral-anal $(\mathrm{OA})$ & 0 & 2 & $2(3)$ \\
\hline \multicolumn{4}{|c|}{ Number of sexual partner in the last month } \\
\hline 0 person & 4 & 23 & $27(33)$ \\
\hline 1 person & 3 & 45 & 48 (59) \\
\hline$\geq 2$ persons & 0 & 6 & $6(8)$ \\
\hline \multicolumn{4}{|c|}{ Number of sexual partner in the last $\mathbf{3}$ months } \\
\hline 0 person & 2 & 18 & $20(25)$ \\
\hline 1 person & 5 & 41 & $46(57)$ \\
\hline$\geq 2$ persons & 0 & 15 & $15(18)$ \\
\hline \multicolumn{4}{|c|}{ Number of lifetime sexual partner } \\
\hline 1 person & 2 & 19 & $21(26)$ \\
\hline $2-5$ persons & 5 & 34 & $39(48)$ \\
\hline$\geq 6$ persons & 0 & 21 & $21(26)$ \\
\hline \multicolumn{4}{|l|}{ Condom use } \\
\hline Never & 2 & 18 & $20(25)$ \\
\hline Seldom & 2 & 19 & $21(26)$ \\
\hline Always & 3 & 37 & 40 (49) \\
\hline \multicolumn{4}{|l|}{ STI history } \\
\hline Positive & 5 & 38 & $43(53)$ \\
\hline Negative & 2 & 36 & $38(47)$ \\
\hline
\end{tabular}


collection kit (Roche Ltd., Basel, Switzerland) and they were transported to the laboratory in transport medium tubes (Roche Ltd., Basel, Switzerland). Both specimens were transported to the laboratory on the day of collection. The DNAs from urine were isolated using Qiamp DNA extraction kit and the DNAs from cervical smears were isolated using Roche preparation kit. PCR for M. genitalium was performed using the PCR kit from Genekam Biotechnology AG. The PCR results were interpreted with agarose gel using a UV chamber. Positive results were established in accordance with the positive control bands (341bp) and no band on the negative control. The data were then stored in a file.

The data were recorded in the prepared research form, then the editing, verification, coding, and data entry were conducted using SPSS 17.0. After that, the collected data were calculated for the percentage of $M$. genitalium positive PCR results. Data on subject characteristics and sexual behaviors were also presented descriptively.

\section{Results}

A total of 81 HIV positive patients were examined as a part of this cross-sectional study in order to determine the $M$. genitalium status. The prevalence of $M$. genitalium infection was $7 / 81$. $M$. genitalium positive result for female was $3 / 33$ and $4 / 48$ males were positive.

\section{Discussion}

Culture examination may take several weeks or even months to grow $M$. genitalium, which makes it impossible to use it for diagnostic purpose in clinical practice. In serological testing, M. genitalium may have cross-reactivity with $M$. pneumoniae due to the similarity in structure, thereby decreasing the specificity of the serological tests. Currently, examination by PCR is the method of choice for the detection of $M$. genitalium and the most published target genes are major adhesin MgPa genes or 16S rRNA gene ${ }^{1,9,16}$ The most sensitive clinical samples for testing $M$. genitalium in females when PCR is used, according to the study performed by Wroblewski et al.,17 is from the vaginal swab (91\%) compared to the cervical smear (53\%) and urine (65\%). However, the vaginal smear examination has not been approved by the Food and Drug Administration. Jensen et al. in Shipitsyna et al. ${ }^{8}$ found that the first void urine in males can detect higher $M$. genitalium infections (98\%) than urethral swabs (82\%).
To our knowledge, this is the first prevalence study of $M$. genitalium infection among HIV positive patients in Indonesia, especially in West Java. In this study, the $M$. genitalium infection prevalence in HIV positive patients in Teratai Clinic of Dr. Hasan Sadikin General Hospital, Bandung was $7 / 81$. The $M$. genitalium positive results for female were found in $3 / 33$ of the subjects and 4/48 were found in males. The results of this study were not much different from previous studies. Research conducted by da Costa et al. ${ }^{13}$ in 2009 in 223 males with HIV-1 who visited the HIV Clinic in Sao Paulo General Hospital has obtained similar results, with the M. genitalium infection was found in $13(6 \%)$ urine samples. Manhas et al. ${ }^{14}$ conducted a study on urine samples of 100 males patients who visited the NGU HIV and STI clinic in Chandigarh India in 2010, i.e. 70 HIV-positive cases and 30 HIV-negative cases. In their study, M. genitalium infection was higher in HIV positive patients (7\%), whereas in HIV negative patients, the infections was only $3 \%$. However, the results showed no statistically significant difference in the frequency of $M$. genitalium infection in HIV positive and HIV negative patients. ${ }^{14}$

Gatski et al. ${ }^{10}$ in 2011 revealed that the prevalence of $\mathrm{M}$. genitalium was $10 \%$ in HIV positive females in an HIV Clinic in New Orleans, the United States, with samples taken from the cervix. In the study by Martinelli et al..$^{12}$ it was found that the prevalence of $M$. genitalium was significantly higher statistically in males with AIDS (56\%) compared to HIV positive patients $(10 \%)$ and the normal population (7\%). This may happen for two reasons: first, defects in humoral and cellular immunity in patients with AIDS, making them more prone to infection; second, the colonization of $M$. genitalium in urethral tract of AIDS patients that was resistant to antibiotics due to the use of broad-spectrum antibiotic prophylaxis in those patients. ${ }^{12}$

This study shows that the average age of patients with PCR $M$. genitalium positive was 32 years old, with the youngest of 26 years old, and the oldest was 36 years old. These results suggested that $M$. genitalium infections generally occur during sexually active ages. It was found by da Costa et al. ${ }^{13}$ that the average age of subjects with positive $M$. genitalium in HIV positive males was 43 years old. Gatski et al. ${ }^{10}$ revealed that the average age of the HIV positive females subjects who were positive for M. genitalium was less than 35 years old, which were the sexually active population. Another study conducted by Anagrius et al. $^{16}$ found that of 946 patients attending an STI clinic in Sweden the median age of $M$. genitalium infection was 
26 years with a range of $17-40$ years.

In this study, the prevalence of $M$. genitalium infection is similar between males and females. Studies that compare the prevalence of STIs in males and females are very limited. There is an extensive agreement that females are more frequently and are more heavily exposed to STIs than males. ${ }^{18}$ This condition may occur because females are more vulnerable to STIs anatomically and they have limitations to seek for STI treatment. 2,19

The education level of subjects with positive M. genitalium infection was similar between high school and academic or university graduates. In contrast to this study, Gatski et al. ${ }^{10}$ found that most of the subjects with positive PCR result for M. genitalium were less educated or equivalent to high school graduates (72\%). Pe'pin et al. ${ }^{20}$ discovered a significant association between M. genitalium infection in Female Sex Worker (FSWs) in West Africa with the level of education from no formal education to elementary school. One of the high risk factors for transmitting STIs is a low level of education. Those with an educational level of high school or less are more frequently exposed to STIs than the academic or university graduates. ${ }^{21}$

The average age of the first sexual intercourse for the group with positive $M$. genitalium result was 21.3 years. In the group with positive M. genitalium, approximately $(6 / 13)$ had their first sexual intercourse before the age of $15 .^{13}$ The first experience of sexual intercourse has a great influence on future sexual behaviors and sexual health. In males, first sexual intercourse at a young age is associated with the number of lifetime sexual partners and high-risk sexual behaviors. In females, the first sexual intercourse at a young age is often associated with early marriage. ${ }^{18}$ In this study, the age of the first sexual intercourse was higher than that of the other studies because the religious values and traditions held in this area are against sex before marriage.

\section{References}

1. Totten PA, Robinson DT, Jensen JS. Genital mycoplasma. In: Holmes KK, Sparling PF, Stamm WE, Piot P, Wasserheit J, Corey L, editors. Sexually transmitted diseases. $4^{\text {th }}$ ed. New York: McGrawHill; 2008. p. 709-29.

2. Uuskula A, Kohl PK. Genital mycoplasmas, including Mycoplasma genitalium as sexually transmitted agents. Int J STD AIDS. 2002;13(2):7985.
Most subjects with positive $M$. genitalium have a heterosexual orientation (6/7). This result is different from that of the da Costa et al. ${ }^{13}$ study which revealed infection of $M$. genitalium in HIV positive males were most common in men who have sex with men (MSM), i.e. 77\%. Research conducted by Andersen et al. ${ }^{22}$ in males found that most subjects (69\%) had sex only with other males in the last 12 months. Aleung et al. ${ }^{23}$ stated that most patients infected with $M$. genitalium are heterosexual, although it is not statistically significant.

Most subjects with positive $M$. genitalium performed genital-to-genital sexual intercourse (6 people). This result was different from the result of da Costa et al. ${ }^{13}$ study that found HIV male patients with positive $M$. genitalium often practice oral sex (38\%).

The use of condoms has only a slight effect on M. genitalium infection. Three subjects who were M. genitalium positive always use condoms and four $M$. genitalium positive subjects never use any condom. In a study performed by Gatski et al., ${ }^{10}$ from 32 HIV positive females with positive $M$. genitalium, most of them used condom in the last vaginal intercourse (78\%). Research conducted by Anagrius et al. ${ }^{16}$ found that the use of condoms cannot protect individuals against $M$. genitalium infection significantly. Condoms will reduce STI transmission to their sexual partner if they are used consistently and correctly. ${ }^{24}$ However, it is difficult to measure the effectiveness of condom. ${ }^{25}$

In summary, the prevalence of $M$. genitalium infection in HIV positive patients based on PCR examination in Teratai Clinic of Dr. Hasan Sadikin General Hospital, Bandung was 9\%. Even though the prevalence of $M$. genitalium infection in HIV positive patients is low in this study, identifying mycoplasma infection based on PCR examination should be considered for routine screening test to reduce the incidence of sexually transmitted diseases in HIV positive patients.
3. Uno M, Deguchi T, Saito A, Yasuda M, Komeda H, Kawada Y. Prevalence of Mycoplasma genitalium in asymptomatic men in Japan. Int J STD AIDS. 1997;8(4):259-60.

4. Taylor-Robinson D, Renton A, Jensen JS, Ison CA, Filatova E, Dmitriev G, et al. Association of Mycoplasma genitalium with acute nongonococcal urethritis in Russian men: a comparison with gonococcal and chlamydial 
urethritis. Int J STD AIDS. 2009;20(4):234-7.

5. Taylor-Robinson D. Mycoplasma genitalium -- an up-date. Int J STD AIDS. 2002;13(3):145-51.

6. Oakeshott P, Aghaizu A, Hay P, Reid F, Kerry S, Atherton $\mathrm{H}$, et al. Is Mycoplasma genitalium in women the "New Chlamydia?" A communitybased prospective cohort study. Clin Infect Dis. 2010;51(10):1160-6.

7. Thurman AR, Musatovova O, Perdue S, Shain RN, Baseman JG, Basemen JB. Mycoplasma genitalium symptoms, concordance, and treatment in highrisk sexual dyads. Int J STD AIDS. 2010;21(3):17783.

8. Shipitsyna E, Savicheva A, Sokolovsky E, Ballard RC, Domeika M, Unemo M, et al. Guidelines for the laboratory diagnosis of Mycoplasma genitalium infections in East European countries. Acta Derm Veneorol. 2010;90(5):461-7.

9. Eastick K, Leeming JP, Caul EO, Horner PJ, Millar MR. A Novel polymerase chain reaction assay to detect Mycoplasma genitalium. Mol Pathol. 2003;56(1):25-8.

10. Gatski M, Martin DH, Theall K, Amedee A, Clark RA, Dumestre J, et al. Mycoplasma genitalium infection among HIV-positive women: prevalence, risk factors and association with vaginal sheeding. Int J STD AIDS. 2011;22(3):155-9.

11. Napierala Mavedzenge $S$, Weiss HA. Association Mycoplasma genitalium and HIV infection: a systematic review and meta-analysis. AIDS. 2009;23(5):611-20.

12. Martinelli F, Garrafa E, Turano A, Caruso A. Increased frequency of detection of ureaplasma urealyticum and Mycoplasma genitalium in AIDS patients without uretral symptoms. J Clin Microbiol. 1999;37(6):2042-4.

13. da Costa FA, da Silva RC, Arruda LB, Montanheiro $P$, da Silva Duarte AJ, Casseb J. Prevalence of Mycoplasma genitalium among HIV-infected men in Sao Paulo city detected by realtime polymerasi chain reaction. Int J STD AIDS. 2010;21(1):23-5.

14. Manhas A, Sethi S, Sharma M, Wanchu A, Kanwar AJ, Kaur K, et al. Association of genital mycoplasmas including Mycoplasma genitalium in HIV infected men with nongonococcal urethritis attending STD \& HIV clinics. Ind J Med Res. 2009;129(3):305-10.

15. Cordova CM, Blanchard A, Cunha RA. Higher prevalence of urogenital mycoplasmas in human immunodeficiency virus-positive patients as compared to patients with other sexually transmitted diseases. J Clin Lab Anal. 2000;14(5):246-53.

16. Anagrius C, Loré B, Jensen JS. Mycoplasma genitalium: prevalence, clinical significance, and transmission. Sex Transm Infect. 2005;81(6):45862.

17. Wroblewski JK, Manhart LE, Dickey KA, Hudspeth MK, Totten PA. Comparison of transcriptionmediated amplification and PCR assay results for various genital spesimen types for detection of Mycoplasma genitalium. J Clin Microbiol. 2006;44(9):3306-12.

18. Buve A, Gourbin CC, Laga M. Gender and sexually transmitted disease. In: Holmes KK, Sparling PF, Stamm WE, Piot $P$, Wasserheit JN, editor. Sexually transmitted disease. $4^{\text {th }}$ ed. New York: McGrawHill; 2008. p. 151-201.

19. Hook EW. Gender differences in risk for sexually transmitted diseases. Am J Med Sci. 2012;343(1):10-1.

20. Pe'pin J, Labbe' A-C, Khonde N, Deslandes S, Alary M, Dzokoto A, et al. Mycoplasma genitalium: an organism commonly associated with cervicitis among west African sex workers. Sex Transm Infect. 2005;81(1):67-72.

21. Lu F, Jia $Y$, Bin S, Li C, Limei S, Kristensen $\mathrm{S}$, et al. Predictors for casual sex and/or infection amongsexually transmitted disease clinic attendees in China. Int J Dermatol. 2009;20(4):241-8.

22. Andersen B, Sokolowski I, Østergaard L, Kjølseth Møller J, Olesen F, Jensen JS. Mycoplasma genitalium prevalence and behaviour risk factor in the general population. Sex Transm Infect. 2007;83(3):237-41.

23. Leung A, Eastick K, Haddon LE, Horn CK, Ahuja D, Horner PJ. Mycoplasma genitalium is associated with symptomatic urethritis. Int J STD AIDS. 2006;17(5):285-8.

24. Garnet JP. The transmision dynamic of sexually transmitted infection. In: Holmes KK, Sparling PF, Stamm WE, Piot P, Wasserheit JN, editors. Sexually transmitted diseases. $4^{\text {th }}$ ed. New York: McGraw-Hill; 2008. p. 27-40.

25. Aral SO, Holmes KK. The epidemiology of STIS and their social and behavioral determinants: industrialized and developing countries. In: Holmes K, Sparling S, Stamm W, Piot P, Wasserheit J, Corey L, editors. Sexually transmitted diseases. $4^{\text {th }}$ ed. New York: McGraw-Hill; 2008. p. 52-97. 